\title{
Diagnóstico e manejo do herpes-zóster pelo médico de família e comunidade
}

\author{
Diagnosis and management of herpes zoster by the family and community physician
}

\section{Diagnóstico y manejo del herpes zoster por el médico de familia y comunidad}

Pedro Alexandre Barreto Coelho. Secretaria Municipal de Saúde do Rio de Janeiro. Rio de Janeiro, RJ, Brasil. coelhopab@gmail.com (Autor correspondente) Priscila Barreto Coelho. Faculdade da Saúde e Ecologia Humana (FASEH). Belo Horizonte, MG, Brasil. pribarretocoelho@hotmail.com Natalia de Campos Carvalho. Secretaria Municipal de Saúde do Rio de Janeiro. Rio de Janeiro, RJ, Brasil. natcampos123@hotmail.com Michael Schmidt Duncan. Secretaria Municipal de Saúde do Rio de Janeiro. Rio de Janeiro, RJ, Brasil. msduncan81@gmail.com

\section{Resumo}

0 herpesvírus que causa a varicela (catapora) persiste de forma latente no sistema nervoso, podendo se reativar e propagar através das raízes nervosas e se manifestar de forma tardia através de lesões cutâneas dolorosas, condição essa denominada herpes-zóster. 0 diagnóstico é primariamente clínico, devendo ser feito diagnóstico diferencial com impetigo, dermatite de contato, dermatite herpetiforme e, também, com o próprio herpes simples. Uma vez confirmado o diagnóstico, o tratamento deve ser instituído nas primeiras 72 horas após a erupção das lesões e tem como base a terapia antiviral. Dentre os antivirais, o valaciclovir e o fanciclovir têm eficácia superior quando comparados ao aciclovir. A complicação mais frequente do herpes-zóster é a neuralgia pós-herpética, usualmente manejada com antidepressivos tricíclicos, anticonvulsivantes, lidocaína tópica ou capsaicina. Recentemente foi introduzida no Brasil uma vacina de vírus atenuado para o herpes-zóster, composta pelo mesmo vírus da vacina contra varicela, porém em concentração maior. Entretanto, essa vacina ainda apresenta custo elevado e não está disponível no Sistema Único de Saúde.

\section{Abstract}

The herpes virus that causes varicella (chickenpox) persists in a latent form in the nervous system and can reactivate and propagate through nerve roots, manifesting years later through painful skin lesions, a condition called herpes zoster. The diagnosis is primarily clinical, but it is important to make a differential diagnosis with impetigo, contact dermatitis, dermatitis herpetiformis and also herpes simplex itself. After the diagnosis is confirmed, treatment should be initiated within the first 72 hours after onset of the rash and it is based upon antiviral therapy. Valacyclovir and famciclovir are more effective when compared to acyclovir. The most common complication of herpes zoster is post-herpetic neuralgia, usually managed with tricyclic antidepressants, anticonvulsants, topical lidocaine or capsaicin. Recently, a live attenuated vaccine against herpes zoster was introduced in Brazil, with the same components as the vaccine against varicella, but in a greater concentration. However, it still has a high cost and is not available in the public health system.

\section{Resumen}

El virus del herpes que causa la varicela persiste en una forma latente en el sistema nervioso, siendo capaz de reactivarse y propagarse a través de las raíces nerviosas, manifestándose tardíamente con lesiones cutáneas dolorosas, una condición denominada herpes zoster. Su diagnóstico es clínico, realizándose el diagnóstico diferencial con impétigo, dermatitis de contacto, dermatitis herpetiforme y con el herpes simple. Una vez confirmado el diagnóstico, el tratamiento debe instaurase en el plazo de las primeras 72 horas después de la aparición de las lesiones y se basa en la terapia antiviral. Entre los antivirales, el valaciclovir y el famciclovir son más eficaces que el aciclovir. La complicación más común del herpes zóster es la neuralgia postherpética, normalmente abordada con antidepresivos tricíclicos, anticonvulsivantes, lidocaína tópica o capsaicina. Recientemente ha sido introducida en Brasil una vacuna con virus vivo atenuado contra el herpes zoster, compuesta por el mismo virus contra la varicela pero a una concentración mayor. De momento, todavía tiene un alto coste y no está disponible en el Sistema Único de Salud.

Palavras-chave: Herpes Zoster Terapêutica Atenção Primária à Saúde

Keywords: Herpes Zoster Therapeutics Primary Health Care

Palavras clave: Herpes Zóster Terapéutica Atención Primaria de Salud 


\section{Introdução}

O vírus varicela-zóster (VVZ) é um herpesvírus que causa a varicela e persiste de forma latente no sistema nervoso após um quadro de infecção primária. A reativação do VVZ em um nervo craniano ou no gânglio dorsal da raiz, com propagação ao longo do nervo sensorial para o dermátomo, leva a manifestaçóes cutâneas dolorosas, condição essa denominada herpes-zóster. ${ }^{1}$

O herpes-zóster é uma doença relativamente comum. A incidência nos Estados Unidos é de 3,0 a 4,0 casos por 1000 pessoas-ano, ${ }^{2}$ semelhante à europeia, que é de 2,0 a 4,6 casos por 1000 pessoas-ano. ${ }^{3}$ Não estáo disponíveis dados sobre a incidência no Brasil.

O principal fator de risco para herpes-zóster é o aumento da idade. Na Europa, a incidência em crianças é de 1 caso em 1000 pessoas-ano, enquanto em adultos com 80 anos ou mais ela é de 10 casos em 1000 pessoas-ano. ${ }^{3}$ Pessoas não vacinadas, que viverão até os 85 anos de idade, têm um risco de $50 \%$ de desenvolverem a doença ao longo da vida. ${ }^{4}$ Após um quadro de varicela (primoinfecção), há uma redução progressiva, proporcional ao tempo, no nível de imunidade mediada pelas células T para o VVZ. ${ }^{5}$ Por outro lado, quando a infecção pela varicela ocorre intraútero, ou no primeiro ano de vida, quando o sistema celular imune ainda não está completamente maduro, aumenta o risco de desenvolver herpes-zóster na infância. ${ }^{4}$

Outros fatores de risco para herpes-zóster são sexo feminino, raça negra e história familiar positiva para a doença. ${ }^{6}$ Pessoas com imunidade diminuída das células T, como os transplantados em uso de terapia imunossupressora, os infectados pelo vírus da imunodeficiência humana (HIV) e os pacientes com linfoma ou leucemia, também estão em maior risco de desenvolver a doença, bem como de desenvolver formas mais graves, com quadros prolongados, recorrentes ou acometendo múltiplos dermátomos e órgãos. ${ }^{7}$

As complicaçôes mais conhecidas e temidas do herpes-zóster são as afecçôes neurológicas, as oftalmológicas e a neuralgia pós-herpética. Dentre as neurológicas, as mais importantes são os ataques isquêmicos transitórios, a paralisia facial e a Síndrome de Ramsey Hunt (herpes-zóster acometendo o ouvido). As oftalmológicas ocorrem principalmente na distribuiçáo do nervo trigêmeo, podendo incluir ceratite, esclerite, uveíte, necrose aguda da retina e conjuntivite. ${ }^{5}$ A neuralgia pós-herpética, dor que persiste após a resolução da erupção cutânea, pode perdurar por muitos meses ou mesmo anos e pode ser grave, interferindo com o sono e atividades da vida cotidiana. A neuralgia pós-herpética é pouco comum em crianças, e sua incidência e gravidade aumentam com a idade. Ocorre em 30\% dos pacientes com mais de 40 anos e é mais frequente quando o nervo trigêmeo é envolvido, situação na qual também são mais frequentes as complicaçôes oftalmológicas. ${ }^{4}$

\section{Manifestações clínicas}

O quadro clínico geralmente inicia com sintomas prodrômicos de dor, mal-estar, febre baixa, prurido e sensibilidade localizada. Na sequência, surge uma erupção cutânea, inicialmente com máculas e pápulas, evoluindo para vesículas, pústulas e crostas (Figuras 1 e 2). Novas lesóes podem aparecer após 3 a 5 dias, apesar da terapia antiviral. A erupção geralmente fica seca, com crostas, em 7 a 10 dias, ${ }^{8}$ sendo que há resolução das lesôes após um período médio de 2 a 3 semanas.

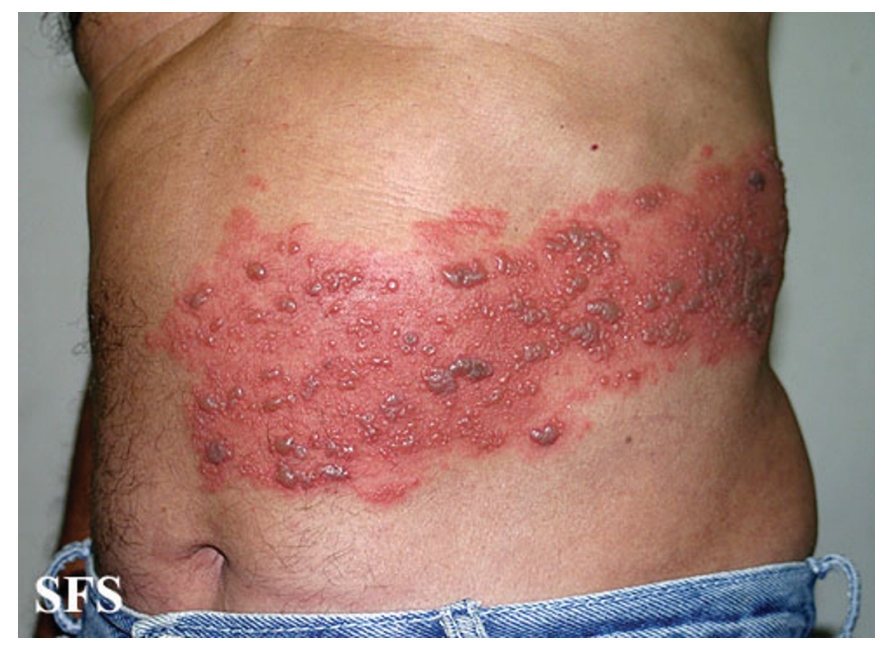

Figura 1. Lesão típica de herpes zoster, acometendo dermátomo em região abdominal. ${ }^{9}$

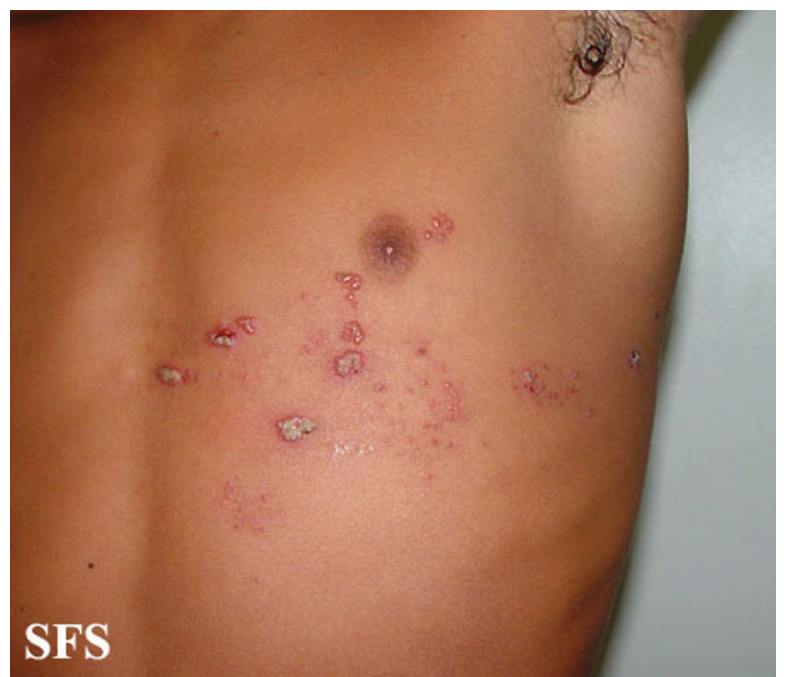

Figura 2. Herpes zoster acometendo dermátomo torácico. ${ }^{9}$ 
A distribuição é dermatômica (ou metamérica - seguindo o trajeto de um nervo), devido à propagaçáo do vírus, podendo afetar qualquer dermátomo, juntamente com as suas mucosas. Raramente a lesão ultrapassa a linha média, característica consistente com o acometimento de um único gânglio dorsal da raiz ou nervo craniano. Os dermátomos torácico, trigeminal, lombar e cervical são os mais acometidos. Em indivíduos imunocomprometidos, podem ocorrer lesôes fora do dermátomo afetado.

A dor que acompanha as erupçóes cutâneas pode se manifestar com características distintas em diferentes pacientes, podendo ser leve ou intensa, em queimação ou lancinante. Pode, ainda, vir acompanhada de sintomas neurosensoriais, como parestesias, disestesias, alodínia ou hiperestesia. ${ }^{4}$

Algumas pessoas, porém, podem manifestar o sintoma de dor mesmo na ausência de erupção cutânea, uma condição rara denominada zoster sine herpete. No outro extremo, pacientes imunocomprometidos podem apresentar erupção cutânea disseminada, com viremia e novas lesóes ocorrendo em até 2 semanas. ${ }^{4}$

\section{Diagnóstico}

A maioria dos casos de herpes-zóster é diagnosticada clinicamente, sem a necessidade de exames complementares. Várias outras patologias cutâneas podem se apresentar de forma semelhante, devendo ser lembradas no diagnóstico diferencial (Tabela 1). O diagnóstico tem maior probabilidade de ser herpes-zóster em pessoas com história prévia conhecida de varicela e com todas as manifestaçôes clássicas: pródromos de dor, erupção cutânea e distribuição em dermátomo. Entretanto, a pessoa pode não lembrar de ter tido varicela, e o herpes-zóster também pode se manifestar de forma atípica, resultando em dúvida diagnóstica. Exemplos incluem apresentação visceral, ausência de erupçáo cutânea e presença de lesôes cutâneas disseminadas, essa última sendo mais comum nos imunocomprometidos. Esses casos com maior dificuldade diagnóstica devem ser avaliados pelo dermatologista ou infectologista.

Tabela 1. Doenças que devem ser consideradas no diagnóstico diferencial do herpes-zóster.

\begin{tabular}{ll}
\hline \multicolumn{1}{c}{ Doença } & \multicolumn{1}{c}{ Característica que ajuda a diferenciar } \\
\hline Impetigo & Caracterizado por máculas, seguidas por vesículas ou pústulas, que se rompem formando crostas melicéricas. A dor, quando presente, não é \\
& intensa, sendo geralmente em queimação. Pode haver prurido. Geralmente localizado em face ou extremidades, sem distribuição em dermátomo. \\
Dermatite de contato & É uma erupção localizada, sem distribuição em dermátomo, com relação topográfica com o agente causador. Pode ser uma reação alérgica \\
& ou irritativa. A remoção do agente causador é importante para a resolução do quadro. \\
Dermatite herpetiforme & Pápulas e vesículas eritematosas, muito pruriginosas, distribuídas simetricamente, predominando nas superfícies extensoras dos cotovelos (em 90\% dos \\
& pacientes), joelhos (30\%), nádega, sacro, ombros e couro cabeludo. A erupção é recorrente, predominando nos meses mais quentes. Está associada à doença \\
& celíaca, embora na maioria das vezes os sintomas intestinais não estejam presentes. A confirmação diagnóstica é por meio de biópsia da lesão cutânea. \\
& Caracterizado por cachos de vesículas dolorosas em base eritematosa, frequentemente precedidas por dor e/ou prurido. As lesões geralmente se \\
Herpes simples & localizam em região oral ou genital, sem a distribuição em dermátomo. Eventualmente podem ter uma distribuição mais extensa, lembrando o herpes- \\
& zóster. Deve-se considerar essa hipótese em casos recorrentes de herpes-zóster, devendo ser feita a diferenciação por meio de exames complementares.
\end{tabular}

Embora o diagnóstico geralmente seja clínico, para casos com maior dificuldade diagnóstica podem ser úteis exames complementares (imunofluorescência direta para o antígeno do VVZ ou reação em cadeia da polimerase - PCR - para o DNA do VVZ, em células coletadas na base da lesão).

\section{Tratamento}

A terapia antiviral com aciclovir, valaciclovir ou fanciclovir é recomendada para todos os pacientes imunocomprometidos com herpes-zóster, bem como para os imunocompetentes com idade igual ou superior a 50 anos, dor moderada ou grave, erupção cutânea severa ou envolvimento fora do tronco. Esses três medicamentos têm eficácia comprovada por ensaios clínicos randomizados em termos de redução da formaçáo de novas lesôes, aceleração da resolução das lesốes já existentes 
e diminuição da intensidade da dor aguda. O tratamento com valaciclovir ou fanciclovir parece ser superior ao tratamento com aciclovir para redução da dor associada ao herpes-zóster, exigindo, ainda, menos doses diárias, apesar de um preço mais elevado. ${ }^{10,11,12}$ Há evidências consistentes de que o aciclovir oral é ineficaz para reduzir a incidência de neuralgia pós-herpética e não há evidências suficientes para recomendar os outros antivirais para esta finalidade. ${ }^{13}$

O tratamento geralmente é prescrito por 7 dias na ausência de complicaçôes do herpes-zóster, e as doses recomendadas são apresentadas na Tabela 2. As evidências estáo bem estabelecidas quando a medicação antiviral é iniciada em até 72 horas após o início da erupção das lesôes, porém muitos especialistas recomendam o inicio mesmo após 3 dias, em casos de novas lesôes na pele ainda aparecendo ou complicaçóes do herpes-zóster presentes. No período prodrômico da doença, o diagnóstico é difícil, pois pode demorar até três semanas para o aparecimento das lesôes cutâneas. Assim, é frequente haver atraso no inicio do tratamento, que mostra melhores resultados quanto antes for instituído. ${ }^{4}$

Tabela 2. Antivirais no tratamento do herpes-zóster.

\begin{tabular}{ll}
\hline \multicolumn{1}{c}{ Medicamento } & \multicolumn{1}{c}{ Posologia } \\
\hline Aciclovir & $800 \mathrm{mg}-5$ vezes ao dia por 7 a 10 dias \\
Fanciclovir & $500 \mathrm{mg}-3$ vezes ao dia por 7 dias \\
Valaciclovir & $1000 \mathrm{mg}-3$ vezes ao dia por 7 dias \\
\hline
\end{tabular}

Os efeitos colaterais mais frequentes dos antivirais são dor abdominal, náuseas, vômitos, cefaleia e tontura. ${ }^{14}$

Aciclovir venoso é recomendado para imunocomprometidos hospitalizados e na presença de complicaçôes neurológicas graves.

O uso de corticoides adicionados à terapia antiviral permanece controverso nos casos do herpes-zóster sem complicaçóes. A administração por curta duraçáo de prednisona parece reduzir a dor aguda, melhorar o desempenho nas atividades da vida diária e reduzir o tempo até a cura. ${ }^{15}$ Entretanto aumenta o risco de infecção secundária e não reduz a incidência de neuralgia pós-herpética. ${ }^{8}$

\section{Complicações e seu manejo}

As principais complicaçôes são dor, que se prolongada é denominada neuralgia pós-herpética, alterações oftalmológicas e alterações otológicas.

\section{Dor e prurido}

A dor é uma complicação frequente do herpes-zóster, e o manejo varia de acordo com sua intensidade. Os opióides, como tramadol, são utilizados para dores mais intensas, enquanto, para dores leves os antiinflamatórios não esteroides (AINE), paracetamol ou dipirona podem ser administrados. ${ }^{4} \mathrm{O}$ prurido também é um sintoma frequente, podendo ser aliviado com loção de calamina.

\section{Neuralgia pós-herpética}

Dor que persiste após a resolução da erupção cutânea é outra complicação temida do herpes-zóster. As definiçốes para neuralgia pós-herpética variam quanto ao tempo mínimo de persistência da dor, variando entre 1 e 6 meses. ${ }^{16}$ A dor pode persistir por muitos meses ou mesmo anos, resultando em anorexia, perda de peso, fadiga e depressão. Entretanto, na maioria das vezes, tem resoluçáo espontânea e, quando a duração é superior a um ano, raramente a dor é muito intensa. Pouco comum em crianças, sua incidência, gravidade e duração aumentam com a idade. Ocorre em $30 \%$ dos pacientes com mais de 40 anos e é mais frequente quando o nervo trigêmeo é envolvido. Medicaçóes avaliadas na literatura para reduzir a dor associada à neuralgia pós-herpética incluem antidepressivos tricíclicos (amitriptilina, nortriptilina, imipramina), agentes anticonvulsivantes (gabapentina e pregabalina), opióides, lidocaína tópica (adesivo de lidocaína) e capsaicina. Se houver 
dificuldade no acesso a gabapentina e a pregabalina, o ácido valpróico e a carbamazepina, apesar de baixa evidência, são opçóes que podem ser tentadas. Terapias combinadas, como anticonvulsivante e antidepressivo tricíclico, ou um opiáceo e anticonvulsivante, têm sido mais eficazes do que monoterapia. A dor pode permanecer mesmo com o tratamento, sendo nesse caso indicado encaminhamento a serviços especializados em dor ou para neurologista.

\section{Alterações oftalmológicas}

Os pacientes com herpes-zóster frequentemente desenvolvem também complicaçóes oftalmológicas, principalmente na distribuição do nervo trigêmeo ou lesóes na ponta ou na região lateral do nariz, com envolvimento do nervo nasociliar. Nesse caso, deve-se encaminhar para avaliação com urgência por um oftalmologista. Além dos antivirais, podem estar indicados outros tratamentos, prescritos pelo oftalmologista, como colírios midriáticos, capazes de reduzir o risco de formação de sinéquias; glicocorticóides tópicos para ceratite, episclerite ou irite; medicamentos para reduzir a pressáo intraocular para o tratamento do glaucoma; e terapia antiviral intravítrea para pacientes imunocomprometidos com necrose de retina. ${ }^{4}$

\section{Alterações otológicas}

Uma complicação que, apesar de rara, merece destaque é a síndrome de Ramsay-Hunt, secundária à infecção dos nervos facial e auditivo. É caracterizada por dor intensa no ouvido, vesículas no canal auditivo, paresia ou paralisia facial e erupção cutânea local. Podem também estar presentes vertigem, zumbido e hipoacusia. $\mathrm{O}$ manejo é semelhante ao descrito na seção Tratamento.

\section{Prevenção do herpes-zóster}

As estratégias para prevenção de herpes zoster incluem orientaçóes para evitar a transmissão e o uso de vacina em pacientes acima dos 60 anos.

\section{Precauções para evitar a transmissão}

Pacientes com herpes-zóster podem transmitir o VVZ a pessoas que não foram vacinadas e não tiveram infecção primária, que poderão, então, desenvolver a varicela. Entretanto, a capacidade de transmissão da doença é inferior à de pessoas com primoinfecção e, ao contrário da varicela, não há risco de transmissão intrauterina quando uma gestante desenvolve herpeszóster. Para as pessoas imunocompetentes com herpes-zóster acometendo um dermátomo, deverá haver precauçóes de contato, e as lesôes devem ser cobertas se possível. Para as pessoas com lesôes disseminadas e para imunodeprimidos com herpeszóster, precauçôes de contato e aérea são necessárias até que todas as lesôes estejam encrustadas. A imunização passiva com imunoglobulina (125 U/kg), dentro de 96 horas da exposição a varicela-zóster é indicada para indivíduos imunodeprimidos suscetíveis e para mulheres grávidas suscetíveis expostos à varicela pela primeira vez, bem como para recém-nascidos cujas mães foram infectadas pouco antes do nascimento. A proteção em geral dura três semanas.

\section{Vacina contra 0 herpes-zóster}

A vacina contra herpes-zóster é recomendada pelo Comitê Consultivo em Práticas de Imunizaçóes (ACIP) do Centro de Controle de Doenças (CDC) norte-americano para pessoas com 60 anos de idade ou mais, com o objetivo de prevenir herpes-zóster e suas complicaçôes. Ela é composta pelo mesmo vírus atenuado presente na vacina contra varicela, porém em concentração 14 vezes superior, e é administrada em dose única. Este ano chegou ao mercado brasileiro, tendo custo ainda bastante elevado. Não há previsão para inclusão no calendário de imunizaçôes do Ministério da Saúde. A eficácia da vacina na prevenção do herpes-zóster é de $70 \%$ para as pessoas de 50 a 59 anos de idade, 64\% para as pessoas de 60 a 69 anos de idade e $38 \%$ para pessoas a partir de 70 anos de idade. ${ }^{17}$ Essa redução da eficácia com o aumento da idade não contraindica a vacinação em idosos, uma vez que essas pessoas são as que têm as apresentações clínicas mais graves. ${ }^{17}$ 


\section{Conclusão}

O herpes-zóster costuma se manifestar clinicamente de forma mais grave, acompanhado de complicaçóes, nos indivíduos com idade mais avançada. Seu diagnóstico, por sua vez, continua sendo primariamente clínico e o médico de família e comunidade desempenha um papel de primeira linha na abordagem do herpes-zóster.

O tratamento tem como base a terapia antiviral, a qual apresenta maiores benefícios nos pacientes que apresentam complicaçóes do herpes-zóster ou que possuem risco elevado de desenvolver formas graves, como os que possuem deficiência da imunidade mediada por células T. Quando instituído, o tratamento deve ser iniciado dentro de 72 horas da erupção cutânea, apresentando maiores resultados quanto antes for iniciado. Dentre as medicaçóes disponíveis, há preferência pelo uso do valaciclovir e do fanciclovir, quando comparados ao aciclovir, devido à maior efetividade no alívio da dor e posologia mais fácil.

A prevenção pode ser feita por meio de vacina de vírus vivo atenuado introduzida recentemente no Brasil, porém não disponível no Sistema Único de Saúde.

Futuramente espera-se que as vacinas contra varicela e o herpes-zóster poderão alterar a epidemiologia e a história natural do herpes-zóster e da neuralgia pós-herpética.

A Tabela 3 resume as recomendações principais para o manejo e a prevenção do herpes-zóster.

Tabela 3. Recomendações para pratica médica usando o sistema SORT (Strength of Recommendation Taxonomy).

\begin{tabular}{l} 
Terapia antivirial deve ser iniciada nas primeiras 72 horas do início da erupção cutânea nos pacientes com herpes-zóster para aumentar a taxa de cura e \\
diminuir a dor. \\
Antidepressivos tricíclicos, opióides ou anticonvulsivantes, como a gabapentina ou pregabalina, devem ser utilizados para alívio da dor da neuralgia \\
pós-herpética. \\
Se necessário o uso de terapia tópica, creme de capsaicina ou o adesivo de lidocaína podem aliviar a dor em pacientes com neuralgia pós-herpética. \\
A vacina para o herpes-zóster deve ser oferecida a paciente com idade igual ou superior a 60 anos para a prevenção do herpes-zóster e da neuralgia \\
pós-herpética. \\
\hline Adaptada de Fashner J e Bell AL. ${ }^{18}$ \\
A= ensaios clínicos randomizados de boa qualidade metodológica ou revisão sistemática desses ensaios clínicos com ou sem metanálise; B = ensaios clínicos ou \\
revisões sistemáticas de ensaios clínicos com qualidade metodológica inferior, estudos observacionais; C = consenso/opinião de especialistas.
\end{tabular}

\section{Referências}

1. Portella AVT, Souza LCB, Gomes JMA. Herpes-zóster e neuralgia pós-herpética. Rev Dor. 2013;14(3):210-215. http://dx.doi.org/10.1590/S1806-00132013000300012.

2. Rimland D, Moanna A. Increasing incidence of herpes zoster among veterans. Clin Infect Dis. 2010;50(7):1000-1005. http://dx.doi.org/10.1086/651078.

3. Pinchinat S, Cebrián-Cuenca AM, et al. Similar herpes zoster incidence across Europe: results from a systematic review. BMC Infect Dis. 2013;13(170). http://dx.doi.org/10.1186/1471-2334-13-170.

4. Cohen Jl. Herpes Zoster. N Engl J Med. 2013;369(3):255-263. http://dx.doi.org/10.1056/NEJMcp1302674.

5. Hayward AR, Herberger M. Lymphocyte responses to varicella zoster virus in the elderly. J Clin Immunol. 1987;7(2):174-178. http://dx.doi.org/10.1007/BF00916011.

6. Hicks LD, Cook-Norris RH, Mendoza N, Madkan V, Arora A, Tyring SK. Family history as a risk factor for herpes zoster: a case-control study. Arch Dermatol. 2008;144(5):603-608. http://dx.doi.org/10.1001/archderm.144.5.603.

7. Jong MD, Weel JFL, Oers MHJ, Boom R, Wertheim-van Dillen PME. Molecular diagnosis of visceral herpes zoster. The Lancet. 2001;357(9274):2101-2102. http://dx.doi.org/10.1016/S0140-6736(00)05199-0.

8. Albrecht MA. Treatment of herpes zoster in the immunocompetent host. UpToDate. 2014 Jun.

9. Silva SF. Dermatology Atlas [Internet]. Herpes zoster. 2014 [acesso em 2014 Aug 19]. Disponível em: http://www.atlasdermatologico.com.br.

10. Degreef H. Famciclovir, a new oral antiherpes drug: results of the first controlled clinical study demonstrating its efficacy and safety in the treatment of uncomplicated herpes zoster in immunocompetent patients. Int J Antimicrob Agents. 1994;4(4):241-246.

http://dx.doi.org/10.1016/0924-8579(94)90024-8. 
11. Beutner KR, Friedman DJ, Forszpaniak C, Andersen PL, Wood MJ. Valaciclovir compared with acyclovir for improved therapy for herpes zoster in immunocompetent adults. Antimicrob Agents Chemother. 1995;39(7):1546-1553. http://dx.doi.org/10.1128/AAC.39.7.1546.

12. Tyring SK, Beutner KR, Tucker BA, Anderson WC, Crooks RJ. Antiviral therapy for herpes zoster: randomized, controlled clinical trial of valacyclovir and famciclovir therapy in immunocompetent patients 50 years and older. Arch Fam Med. 2000;9(9):863. http://dx.doi.org/10.1001/archfami.9.9.863.

13. Chen N, Li Q, Yang J, Zhou M, Zhou D, He L. Antiviral treatment for preventing nerve pain after shingles (postherpetic neuralgia). Cochrane Database Syst Rev. 2014;(2). CD006866. http://dx.doi.org/10.1002/14651858.CD006866.pub3.

14. Li Q, Chen N, Yang J, Zhou M, Zhou D, Zhang Q, He L. Antiviral treatment for preventing postherpetic neuralgia. Cochrane Database Syst Rev. 2009;2(2). CD006866. http://dx.doi.org/10.1002/14651858.CD006866.pub2.

15. Whitley RJ, Weiss H, Gnann Jr JW, Tyring S, Mertz GJ, Pappas PG, et al. Acyclovir with and without prednisone for the treatment of herpes zoster: a randomized, placebo-controlled trial. Ann Intern Med. 1996;125(5):376-383. http://dx.doi.org/10.7326/0003-4819-125-5-199609010-00004.

16. Dubinsky RM, Kabbani H, El-Chami Z, Boutwell C, Ali H. Practice parameter: treatment of postherpetic neuralgia: an evidence-based report of the Quality Standards Subcommittee of the American Academy of Neurology. Neurology. 2004 Sep 28;63(6):959-65 (reaffirmed Feb 2008). htpp://dx.doi.org/10.1212/01.WNL.0000140708.62856.72.

17. Oxman MN, Levin MJ, Johnson GR, Schmader KE, Straus SE, Gelb LD, et al. A vaccine to prevent herpes zoster and postherpetic neuralgia in older adults. N Engl J Med. 2005;352(22):2271-2284. http://dx.doi.org/10.1056/NEJMoa051016.

18. Fashner J, Bell LA. Herpes Zoster and postherpetic neuralgia: prevention and management. Am Fam Physician. 2011;83(12):1432-1437. 